\title{
ELABORAÇÃO DE UM INVENTÁRIO DE RESÍDUOS SÓLIDOS PARA UMA COOPERATIVA DE DISTRIBUIÇÃO DE ENERGIA ELÉTRICA
}

\section{DEVELOPMENT OF A SOLID WASTE INVENTORY FOR AN ELECTRICITY DISTRIBUTION COOPERATIVE}

\section{Émilin de Jesus Casagrande de Souza Bacharel em Engenharia Ambiental pela Universidade do Extremo Sul Catarinense (UNESC). E-mail: emilinjc@hotmail.com}

Sergio Luciano Galatto Professor pela Universidade do Extremo Sul Catarinense (UNESC). E-mail: sga@unesc.net

\section{RESUMO}

O processo de produção industrial é muito variado, gerando uma quantidade significativa de resíduos sejam eles, sólidos, líquidos e gasosos. Dependendo da indústria, o processo pode variar bem como o tipo de resíduos e suas respectivas destinações, ou seja, alguns podem ser recicláveis ou reaproveitáveis. Desta forma, desenvolveu-se este trabalho em uma cooperativa de distribuição de energia, situada na região Sul de Santa Catarina, tendo como objetivo a elaboração de um inventário de resíduos sólidos. Foi realizada uma pesquisa teórica através do levantamento de dados secundários referentes ao tema proposto, com objetivo de criar um embasamento técnico-científico que pode auxiliar no esclarecimento e resolução do problema apresentado bem como o levantamento das informações quanto ao gerenciamento dos resíduos sólidos gerados na cooperativa, levando em consideração, geração, separação, coleta, tratamento e destinação final.

Palavras-chave: Processo Industrial. Resíduos. Inventário de Resíduos Sólidos.

\begin{abstract}
The industrial production process is very variable, generating a significant amount of solid, liquid and gaseous waste. Depending on the industry, the process can vary as well as the type of waste and their respective destinations, i.e., some may be recyclable or reusable. In this way, this work was developed in an energy distribution cooperative, located in the southern region of Santa Catarina, aiming the elaboration of an inventory of solid waste. A theoretical research was carried out through the collection of secondary data referring to the proposed theme, with the objective of creating a technical-scientific base that could help in the clarification and resolution of the presented problem as well as the information gathering regarding solid waste management in the cooperative, taking into consideration, generation, separation, collection, treatment and final destination.
\end{abstract}

Keywords: Process Industries. Waste. Solid Waste Inventory. 
Revista Tecnologia e Ambiente, v. 23, 2017, Criciúma, Santa Catarina/SC

ISSN Eletrônico 2358-9426 e ISSN Impresso 1413-8131

\section{INTRODUÇÃO}

A partir da década de 1980, as problemáticas ambientais tornarem-se mais populares, fazendo parte do cotidiano dos meios de comunicação, publicadas em jornais, revistas e noticiários, registrando, por exemplo, desastres ecológicos que passaram a fazer parte do diaa-dia (BRUGGER, 1994 p.48).

Segundo Oliveira (2002), logo que surgiram as primeiras indústrias os problemas ambientais eram pequenos, pois a população era menor e a produção em baixa escala, sendo mínimas as exigências de controle ambiental, bem como diretrizes de legislações específicas. Foi por volta da década de 1970 que as questões ambientais passaram a ser levadas mais em consideração, ou seja, as empresas deixaram de serem vistas apenas como instituições econômicas, mas sim como sociais, políticas e ambientais, com o controle da poluição, segurança, qualidade dos produtos e maior assistência social bem como o gerenciamento correto dos resíduos gerados em seu processo produtivo.

O processo de produção industrial é muito variado fazendo com que gere uma quantidade significativa de resíduos sejam eles, sólidos, líquidos e gasosos. Dependendo da indústria o processo pode variar bem como o tipo de resíduos e suas respectivas destinações, ou seja, alguns podem ser recicláveis ou reaproveitáveis. O descarte indevido desses resíduos acaba por prejudicar o ecossistema bem como pode comprometer a saúde humana, sendo assim o gerenciamento desses resíduos consiste em procedimentos de gestão, planejamento a fim de minimizar a produção dos resíduos bem como proporcionar a destinação final adequada.

Desta forma desenvolveu-se este trabalho em uma cooperativa de distribuição de energia, situada na região sul de Santa Catarina, tendo como objetivo a elaboração de um inventário de resíduos sólidos, ferramenta esta que fornece as informações necessárias quanto às características, armazenamento, transporte, tratamento, reutilização, reciclagem dos resíduos sólidos gerados pela cooperativa, visando a busca de melhorias a fim de promover a sustentabilidade ambiental da mesma.

\section{Resíduos Sólidos}

De acordo com Faria (2013), até um determinado período os resíduos eram definidos como algo que não apresentava utilidade e nem valor comercial, porém com o passar dos anos e da criação de políticas voltadas ao gerenciamento e classificação dos resíduos sólidos, esses materiais passaram a adquirir um valor econômico. Atualmente, a maior parte desses resíduos 


\section{Revista Tecnologia e Ambiente, v. 23, 2017, Criciúma, Santa Catarina/SC ISSN Eletrônico 2358-9426 e ISSN Impresso 1413-8131}

é aproveitada de forma direta como, por exemplo, a utilização das aparas de embalagens laminadas descartadas pelas indústrias para confecção de placas e compensados, ou ainda de forma indireta como combustível para geração de energia podendo ser utilizada em diversos processos.

A Política Nacional de Resíduos Sólidos (PNRS) através da Lei n. 12.305/2010 descreve resíduo sólido como todo material, substância, objeto ou bem descartável oriundo das atividades humanas em seus estados sólido ou semissólido, bem como gases e líquidos a qual suas particularidades tornem invisíveis o lançamento na rede pública de esgoto e em corpos d'água sem possuírem soluções técnicas e econômicas inviáveis em relação à escolha da melhor tecnologia disponível (BRASIL, 2010 p.1).

A Norma Brasileira Regulamentada (NBR) 10.004/04 define resíduo sólido como:

Resíduos nos estados sólido e semissólido, que resultam de atividades de origem industrial, doméstica, hospitalar, comercial, agrícola, de serviços e de varrição. Ficam incluídos nesta definição os lodos provenientes de sistemas de tratamento de água, aqueles gerados em equipamentos e instalações de controle de poluição, bem como determinados líquidos cujas particularidades tornem inviável o seu lançamento na rede pública de esgotos ou corpos de água, ou exijam para isso soluções técnicas economicamente inviáveis em face à melhor tecnologia disponível (ABNT, 2004, p.1).

São constituídos de materiais heterogêneos (inertes, minerais e orgânicos) que resultam das atividades humanas e da natureza, dos quais podem ser parcialmente utilizados. Trazem problemas sanitário, econômico e estético, uma vez que possuem substâncias facilmente degradantes (FD) - resto de comidas, sobras de cozinha, folhas, casca de frutas, animais mortos e excremento, moderadamente degradantes (MD) - papel, papelão e outros produtos celulósicos, dificilmente degradante (DD) - trapo, couro, pano, madeira, borracha entre outros, não degradantes (ND) - metal não ferroso, vidros, pedras, cinzas, terra, areia, cerâmicas. Sua composição pode variar de comunidade para comunidade conforme os hábitos e costumes da população, número de habitantes, poder aquisitivo, variações sazonais, clima, desenvolvimento econômico e nível educacional (LIMA, 2005 p.40).

A contaminação do meio ambiente pelos resíduos provoca direta e indiretamente efeitos nocivos no ser humano, através de agentes como o solo, ar, água ou alimentos tanto de origem vegetal como animal, e quando contaminados transferem os malefícios para a cadeia biológica (BRASIL. SANTOS, 2007 p.78). 


\section{Revista Tecnologia e Ambiente, v. 23, 2017, Criciúma, Santa Catarina/SC \\ ISSN Eletrônico 2358-9426 e ISSN Impresso 1413-8131}

\section{Classificação}

Ao se caracterizar o resíduo sólido devem-se determinar suas principais características físicas, químicas, qualitativa e/ou quantitativamente a qual depende da abrangência e aplicação do resultado que se quer obter. A caracterização dos resíduos exige o conhecimento de sua origem, constituintes e características conforme padrões específicos de amostragens e testes que determinam, por exemplo, se o resíduo é inflamável, corrosivo, combustível, tóxico entre outros. Estudam-se ainda suas propriedades físicas (granulométrica, peso, volume, resistência mecânica etc.) e químicas (reatividade, composição, solubilidade, etc.) (FARIA 2013b p.3).

Valle (2002) destaca que a classificação dos resíduos gerados ou acumulados em um estabelecimento é de grande importância para a escolha de uma melhor solução quanto ao seu tratamento ou disposição.

De acordo com a NBR 10.004/2004, a classificação dos resíduos envolve a identificação do processo ou atividade a qual lhes deu origem, suas características bem como a comparação desses resíduos com substâncias que são nocivas a saúde e ao meio ambiente, sendo classificado da seguinte forma:

- Quanto a sua natureza física: seco e molhado;

- Quanto a sua composição química: matéria orgânica e matéria inorgânica;

- Quanto aos riscos potenciais ao meio ambiente: perigosos, não inertes e inertes;

- Quanto à origem: domiciliar, comercial, industrial, serviços de saúde, portos aeroportos, terminais ferroviários e rodoviários, agrícola, construção civil, limpeza (lavadouros, praias, feiras, eventos, etc. abatedouros de aves, matadouros, estábulos e serviços congêneres) (LIMA, 2005 p.8).

\section{Gerenciamento de Resíduos Sólidos}

O gerenciamento de resíduos sólidos diz respeito aos aspectos tecnológicos e operacionais os quais envolvem fatores administrativos, gerenciais, econômicos, ambientais e de desempenho quanto à qualidade e produtividade de prevenção, redução, segregação, reutilização, acondicionamento, coleta, transporte, tratamento, recuperação de energia e destinação final (LIMA, 2005 p.4).

Constitui também um conjunto de procedimentos de gestão ambiental de forma planejada e implementada para a minimização da geração de resíduos e a adequada coleta 


\section{Revista Tecnologia e Ambiente, v. 23, 2017, Criciúma, Santa Catarina/SC \\ ISSN Eletrônico 2358-9426 e ISSN Impresso 1413-8131}

seletiva, visando a preservação da saúde pública e a qualidade do meio ambiente (SEMAD, 2010 p.9).

Um bom gerenciamento exige o emprego de técnicas eficazes para a solução da problemática que envolve uma complexa relação interdisciplinar e abrange aspectos políticos e geográficos, o planejamento local e regional e o elemento sociológico e demográfico (LIMA, 2005 p.4).

\footnotetext{
A Política Nacional dos Resíduos Sólidos (PNRS) define gerenciamento como um conjunto de ações exercidas, direta ou indiretamente, nas etapas de coleta, transporte, transbordo, tratamento e destinação final ambientalmente adequada, e de acordo com o plano municipal de gestão integrada de resíduos sólidos ou com plano de gerenciamento de resíduos sólidos (BRASIL, 2010 p.3).
}

\section{Etapas do Sistema de Gerenciamento de Resíduos Sólidos}

\section{a) Armazenamento}

A ABNT 12235/1992, define armazenamento como a contenção temporária em uma determinada área autorizada pelos órgãos de controle e fiscalização ambiental, que se encontram a espera de reciclagem, recuperação, tratamento ou disposição final adequada atendendo a uma série de condições básicas de segurança.

Os resíduos classificados como perigosos Classe I, segundo a NBR 10004/2004, não devem ser armazenados juntamente com os demais resíduos classificados como não perigosos.

\section{b) Acondicionamento}

O acondicionamento dos resíduos sólidos está relacionado à sua preparação para coleta adequada considerando tipo e quantidade. Apresenta vantagens como: evitar acidentes e proliferação de vetores, minimizar o impacto visual e olfativo, reduzir a heterogeneidade (caso haja coleta seletiva) e facilitar a etapa da coleta (JUNIOR, 2010 p.78).

Ainda segundo Junior (2010), durante o acondicionamento o recipiente apropriado para os resíduos deverá:

Atender as condições sanitárias;

Estar em boas condições;

Ter capacidade para conter o resíduo gerado durante o intervalo entre uma coleta e outra;

Permitir uma coleta rápida, aumentando a produtividade do serviço; 
Revista Tecnologia e Ambiente, v. 23, 2017, Criciúma, Santa Catarina/SC

ISSN Eletrônico 2358-9426 e ISSN Impresso 1413-8131

Possibilitar manutenção segura por parte das equipes de coleta.

Conforme Brasil e Santos (2007), o que determina a escolha do tipo de recipiente adequado para cada caso são as características dos resíduos, a quantidade de material a ser acondicionado, tipo de transporte a ser utilizado e sua disposição adequada.

De acordo com a NBR 12235/92, todos os resíduos perigosos devem ser acondicionados temporariamente para possíveis tratamentos, como, reciclagem, recuperação, tratamento, disposição final, podendo ser realizados em contêineres, tambores, tanques ou a granel.

Resol (2012) informa que os resíduos sólidos devem ser acondicionados em sacos plásticos, incluso no interior dos recipientes (lixeiras); confeccionados com material lavável que resiste a punctura, ruptura e vazamento; apresentar tampa proveniente de um sistema aberto sem contato manual; cantos arredondados que resistem ao tombamento.

\section{c) Transporte}

De acordo com Afumag (2013), o transporte consiste no recolhimento dos resíduos e seu possível encaminhamento para o tratamento e/ou disposição final ambientalmente adequado. Os resíduos são coletados a fim de evitar problemas ambientais e de saúde pública, sendo os procedimentos de coleta adequados aos aspectos básicos como regularidade, frequência, horários e itinerários.

A NBR 13221/2003 coloca que o transporte deve ser realizado com equipamentos adequados, não permitindo vazamento ou derramamento, devendo estar devidamente acondicionado para que o mesmo não se espalhe em vias públicas, sempre em atendimento as legislações vigentes.

A Lei n. 12.305/2010 (BRASIL, 2010) define que os resíduos considerados de transporte são aqueles oriundos de portos, aeroportos, terminais alfandegários, rodoviários e ferroviários e de passagem de fronteira.

Conforme Brasil e Santos (2007) a modalidade de transporte predominante no Brasil é o rodoviário, em função de seu menor custo e distância. Os veículos utilizados são:

Caminhão Tipo Poliguindaste: recomendado para resíduos a granel, com toxidade baixa ou moderada, não reativos ou corrosivos;

Caminhão Tipo Basculante: recomendado para transporte de resíduos a granel, com toxidade baixa ou moderada, não corrosivos ou reativos; 
Revista Tecnologia e Ambiente, v. 23, 2017, Criciúma, Santa Catarina/SC

ISSN Eletrônico 2358-9426 e ISSN Impresso 1413-8131

Caminhão Tanque: recomendado para resíduos líquidos ou fluidos a granel, quando corrosivos se indica revestimento específico;

Caminhão Carroceria Aberta: recomendado para o transporte de todo tipo de resíduo, sólido, líquido e pastoso devidamente acondicionado.

\section{d) Tratamento}

O tratamento dos resíduos sólidos possui três finalidades: i) reduzir ou eliminar sua periculosidade; ii) imobilizar seus componentes perigosos; iii) reduzir o volume do mesmo ainda depois de tratado requer cuidados especiais, ou seja, tratar um resíduo consiste em transformá-lo em um novo produto e posteriormente reutilizá-lo ou até mesmo dar uma destinação adequada tanto para os industriais perigosos ou os urbanos. Esse processo pode ser classificado em quatro tipos básicos: físicos, químicos, biológicos e térmicos (VALLE, 2002 p.48).

Tratamento Físico: Apresenta como finalidade reduzir o volume e imobilizar os componentes neles contidos. Possui a operação e secagem, centrifugação, evaporação, sedimentação, floculação, filtração, adsorção, destilação, concentração entre outros;

Tratamento Químico: São utilizados na eliminação de componentes tóxicos, substituição dos contaminantes por compostos mais instáveis, produção de novos compostos com valor comercial e transformação dos resíduos em materiais insolúveis. Apresentam tratamentos como neutralização, oxidação, redução e precipitação;

Tratamento Biológico: Consiste na utilização de micro-organismos que aceleram o processo natural de degradação biológica dos resíduos com cargas orgânicas elevadas;

Tratamento Térmico: Incluem a incineração e a pirólise a qual consistem em processos físico-químicos que em altas temperaturas alteram as características dos resíduos.

\section{Disposição Final}

As áreas para disposição final necessitam de rigorosos padrões de seleção, ou seja, devem-se evitar locais com solo muito permeável, com fraturas rochosas, sujeitos a instabilidades sísmicas e áreas de proteção ambiental e de preservação permanente. Existe carência de se encontrar locais adequados para instalação de aterros sanitários e industriais, aliado ainda as questões socioambientais de resistência das pessoas em quererem aterros 


\section{Revista Tecnologia e Ambiente, v. 23, 2017, Criciúma, Santa Catarina/SC \\ ISSN Eletrônico 2358-9426 e ISSN Impresso 1413-8131}

próximos as suas localidades. Este fato associado à falta de fiscalização e controle dos órgãos ambientais, tem promovido ao costume de lançar os resíduos em quaisquer locais "bota fora", ou muitas vezes os resíduos sendo misturados (domiciliares com industriais ou com de construção civil) (JUNIOR, 2005 p.5).

De acordo com Fariac (2013), a partir da classificação dos resíduos pela NBR 10004/04, são determinadas as destinações adequadas para cada tipo de resíduo. A disposição final dos resíduos sólidos considera como sendo "distribuição ordenada de rejeitos em aterros, observando normas operacionais específicas de modo a evitar danos ou riscos à saúde pública e à segurança e a minimizar os impactos ambientais adversos" (BRASIL, 2010 p.3).

Dessa forma, tem-se um destino diferente para cada grupo em razão de seu potencial ou valor econômico, ou seja, para os resíduos haverá a destinação aos processos de reciclagem, reutilização ou aproveitamento econômico, por meio dos quais permanecerão por mais tempo inseridos na cadeia produtiva. Para os rejeitos ocorrerá a disposição final em aterros sanitários nos quais serão gradualmente degradados mediante processos biológicos ou, alternativamente, poderão gerar energia elétrica a partir dos processos de queima controlada (QUINTIRIE, 2013 p.1).

\section{METODOLOGIA}

Inicialmente foi realizada uma pesquisa teórica através do levantamento de dados secundários referentes ao tema proposto, com objetivo de criar um embasamento técnicocientífico que pode auxiliar no esclarecimento e resolução do problema apresentado bem como o levantamento das informações quanto ao gerenciamento dos resíduos sólidos gerados na cooperativa, descrevendo a situação do gerenciamento de resíduos sólidos implantado, levando em consideração, geração, separação, coleta, tratamento e destinação final.

Logo após realizou-se a análise de documentos (licenças ambientais, outros), visitas in loco, registros fotográficos, e a qualificação dos resíduos por setor, avaliando a melhor forma de destinação aos mesmos. Na realização do inventário foram levantados todos os resíduos gerados junto aos setores da cooperativa, bem como sua classificação atendendo a NBR 10004/2004 e a Resolução 313/02. Para o levantamento do inventário seguiu-se as orientações apresentados na Tabela 1 .

Tabela 1 - Metodologia utilizada para realizar o inventário de resíduos

\begin{tabular}{lllllll}
\hline \multirow{2}{*}{$N^{\circ}$ Setor/Área Atividade } & \multirow{2}{*}{ Resíduos } & Tipo & \multirow{2}{*}{ Classificação } & $\begin{array}{l}\text { NBR } \\
10004 / 04\end{array}$ & $\begin{array}{l}\text { RES } \\
\mathbf{3 1 3 / 0 2}\end{array}$ \\
\hline
\end{tabular}




\section{Fonte: autores, 2013}

\section{RESULTADOS E DISCUSSÕES}

Com base nos resíduos gerados em cada setor da cooperativa, foi realizada a catalogação e classificação (Figura 1), dando origem ao inventário de resíduos sólidos. Este inventário foi realizado num período de dois meses, com frequência quinzenal, totalizando quatro amostragens.

Salienta-se que a origem dos resíduos gerados na cooperativa sãos provenientes de diferentes setores, tais como: Assembleia Geral; Jurídico; Gerência Administrativa; Departamento de Projetos; Departamento de Compras, dentre outros.

No inventário, foram listados 244 diferentes tipos de resíduos, sendo que optou-se por construir uma síntese para facilitar a análise dos resíduos (Tabela 2). Ressaltamos que os resíduos que não apresentam tecnologias de reciclagem na região foram considerados como não recicláveis.

Figura 1 - Classificação e catalogação dos resíduos.

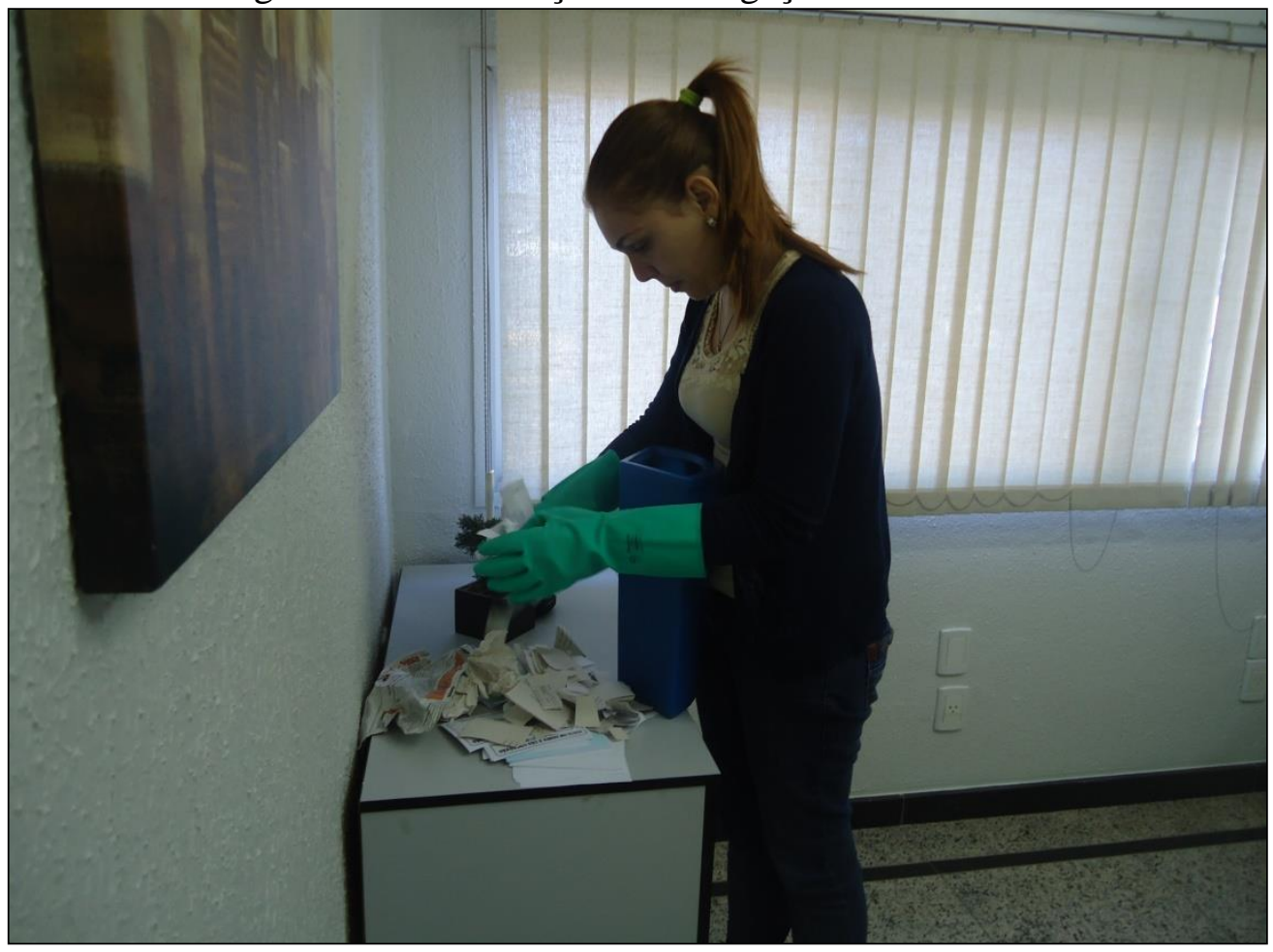

Fonte: Acervo da Autora (2013). 
Revista Tecnologia e Ambiente, v. 23, 2017, Criciúma, Santa Catarina/SC

ISSN Eletrônico 2358-9426 e ISSN Impresso 1413-8131

Tabela 2 - Síntese do inventário de resíduos sólidos gerados nos setores da cooperativa.

\begin{tabular}{|c|c|c|c|c|}
\hline $\mathbf{N}^{\circ}$ & Resíduos & Tipo & Classe & Categoria \\
\hline 1 & Embalagem Plástica & Plástico & IIB & Reciclável \\
\hline 2 & Papel Comum & Papel & IIB & Reciclável \\
\hline 3 & Papel reciclável & Papel & IIB & Não Reciclável \\
\hline 4 & Casca de Frutas & Orgânico & IIA & Não Reciclável \\
\hline 5 & Papel Cartão & Papel & IIB & Reciclável \\
\hline 6 & Papel de Bala & Papel & IIA & Não Reciclável \\
\hline 7 & Copo Descartável & Plástico & IIB & Reciclável \\
\hline 8 & Caneta & Caneta & IIA & Não Reciclável \\
\hline 9 & Papel Laminado com Plástico & Papel Laminado com Plástico & IIB & Não Reciclável \\
\hline 10 & Guardanapo & Papel & IIB & Não Reciclável \\
\hline 11 & Fita Adesiva & Fita Adesiva & IIB & Não Reciclável \\
\hline 12 & Papel Envelope & Papel & IIB & Reciclável \\
\hline 13 & Chips & Metal & IIB & Não Reciclável \\
\hline 14 & Grampo & Metal & IIB & Não Reciclável \\
\hline 15 & Sachê de chá & Orgânico & IIA & Não Reciclável \\
\hline 16 & Isopor & Plástico & IIA & Não Reciclável \\
\hline 17 & Papel Carbono & Papel & IIA & Não Reciclável \\
\hline 18 & Aparas de Papel & Papel & IIB & Reciclável \\
\hline 19 & Lenço de Papel & Papel & IIB & Não Reciclável \\
\hline 20 & Garrafinha PET & Plástico & IIB & Reciclável \\
\hline 21 & Sacola Plástica & Plástico & IIB & Reciclável \\
\hline 22 & Embalagem de Pipoca & Papel & IIA & Não Reciclável \\
\hline
\end{tabular}


Revista Tecnologia e Ambiente, v. 23, 2017, Criciúma, Santa Catarina/SC

ISSN Eletrônico 2358-9426 e ISSN Impresso 1413-8131

\begin{tabular}{|c|c|c|c|c|}
\hline $\mathbf{N}^{\circ}$ & Resíduos & Tipo & Classe & Categoria \\
\hline 23 & Colher Plástica & Plástico & IIB & Reciclável \\
\hline 24 & Embalagem Barra de Cereal & Plástico & IIB & Não Reciclável \\
\hline 25 & Filtro de Papel & Papel & IIB & Não Reciclável \\
\hline 26 & Metal & Metal & IIA & Reciclável \\
\hline 27 & Plástico Bombom & Plástico & IIB & Não Reciclável \\
\hline 28 & Papel Envelope & Papel & IIB & Reciclável \\
\hline 29 & Parafuso & Metal & IIA & Reaproveitável \\
\hline 30 & Borracha & Borracha & IIB & Não Reciclável \\
\hline 31 & Caixa de Leite & Plástico & IIB & Reciclável \\
\hline 32 & Carregador Celular & Metal & I & Não Reciclável \\
\hline 33 & Pilha & Metal & IIB & Reciclável \\
\hline 34 & Embalagem de Bolacha & Plástico & IIB & Reciclável \\
\hline 35 & Chiclete & Chiclete & IIB & Não Reciclável \\
\hline 36 & Telefone & Telefone & IIB & Reutilizável \\
\hline 37 & Cabos & Cabos & IIB & Não Reciclável \\
\hline 38 & Cartucho Tinta de Impressora & Cartucho Tinta de Impressora & I & Não Reciclável \\
\hline 39 & Fio de Cobre & Cobre & IIB & Reciclável \\
\hline 40 & Embalagem de Produto de Limpeza & Plástico & ÍIB & Reciclável \\
\hline 41 & Panos de Limpeza & Têxtil & IIB & Não Reciclável \\
\hline 42 & Papel Higiênico & Papel & IIA & Não Reciclável \\
\hline 43 & Papel Toalha & Papel & IIA & Não Reciclável \\
\hline 44 & Lâmpadas Fluorescente & Lâmpadas & I & Não Reciclável \\
\hline
\end{tabular}


Revista Tecnologia e Ambiente, v. 23, 2017, Criciúma, Santa Catarina/SC

ISSN Eletrônico 2358-9426 e ISSN Impresso 1413-8131

\begin{tabular}{|c|c|c|c|c|}
\hline $\mathbf{N}^{\circ}$ & Resíduos & Tipo & Classe & Categoria \\
\hline 45 & Lâmpadas de Mercúrio & Lâmpadas & I & Não Reciclável \\
\hline 46 & Pano sujo com Óleo e Graxa & Têxtil & IIB & Não Reciclável \\
\hline 47 & Alumínio & Alumínio & IIB & Reciclável \\
\hline 48 & Ferro & Metal & IIB & Reciclável \\
\hline 49 & Cobre & Metal & IIB & Reciclável \\
\hline 50 & Transformadores & Transformadores & IIB & Reciclável \\
\hline 51 & Óleo de Transformador & Óleo & I & Reutilizável \\
\hline 52 & Capacete & Plástico & IIB & Reciclável \\
\hline 53 & Luvas & Borracha & IIB & Não Reciclável \\
\hline 54 & Cruzetas de Madeira & Madeira & IIB & Reaproveitável \\
\hline 55 & Isolante de Porcelana & Porcelana & IIB & Reciclável \\
\hline 56 & Material Misto (Plástico com Metal) & Material Misto (Plástico com Metal) & IIB & Não Reciclável \\
\hline 57 & Sucata de Poste & Sucata de Poste & IIB & Reutilizável \\
\hline 58 & Resto de Comida & Orgânico & IIB & Não Reciclável \\
\hline 59 & Embalagem Tetra Pak & Plástico & IIB & Não Reciclável \\
\hline 60 & Latinha de Refrigerante & Alumínio & IIB & Reciclável \\
\hline 61 & Pacote de Chips & Plástico & IIB & Não Reciclável \\
\hline 62 & Luvas de Limpeza & Plástico & IIB & Não Reciclável \\
\hline 63 & Prato Plástico & Plástico & IIA & Reciclável \\
\hline 64 & Caixa de Papelão & Papel & IIB & Reciclável \\
\hline 65 & Borra de Café & Orgânico & IIA & Reciclável \\
\hline
\end{tabular}

Fonte: autores, 2013 
Revista Tecnologia e Ambiente, v. 23, 2017, Criciúma, Santa Catarina/SC

ISSN Eletrônico 2358-9426 e ISSN Impresso 1413-8131

A partir da síntese do inventário, foram identificados 65 tipos de resíduos, dentre os quais, 34 foram classificados como não recicláveis e 31 como recicláveis, reutilizáveis ou reaproveitáveis no processo produtivo ou por empresas terceirizadas.

De todos os resíduos classificados, grande parte apresenta destinação estabelecida, uma vez que em todos os setores há lixeiras padronizadas (papel, plástico, vidro e metais), sendo que duas vezes por semana a colaboradora responsável pela limpeza, coleta esses resíduos e os destina ao pátio externo da cooperativa em seus boxes de madeira específicos e separados para cada tipo de resíduo (alumínio, plástico, papelão, ferro, cobre, dentre outros).

Esses resíduos são acumulados e ficam armazenados até as empresas terceirizadas irem coletá-los. Há quatro empresas terceirizadas responsáveis pela coleta e disposição dos resíduos.

Uma dessas empresas é responsável pela coleta das estopas, luvas e demais resíduos sólidos contaminados com óleo lubrificante, pilhas, baterias e óleos refinados (classe I) oriundos dos serviços de manutenção realizados nos postes e transformadores. A coleta dos resíduos de papel, plástico, metais, alumínio, ferro e cobre (IIB) é realizado por outra empresa terceirizada.

Por fim, os resíduos de informática (IIB/IIA) são coletados por uma empresa especializada e a coleta das lâmpadas e dos demais resíduos, como restos de alimentos, é realizada pelo sistema de coleta municipal, de responsabilidade da prefeitura, e posteriormente encaminhado ao aterro sanitário local.

\section{CONCLUSÃO}

O inventário de resíduos sólidos nos permitiu levantar os principais resíduos gerados na cooperativa e a sua classificação quanto ao reaproveitamento, reciclagem, armazenamento, bem como a sua destinação final.

A cooperativa possui uma central de resíduos sólidos, onde os resíduos ficam armazenados até sua respectiva destinação final, sendo que os resíduos como papel, plástico, lâmpadas e metais são comprados por uma empresa de reciclagem, que podem ou não repassar tais resíduos para outra empresa terceirizada para a correta disposição destes.

Vale lembrar que durante o inventário foi realizada apenas a qualificação dos resíduos, sendo sugerida a quantificação para um melhor controle dos resíduos sólidos gerados. 
Revista Tecnologia e Ambiente, v. 23, 2017, Criciúma, Santa Catarina/SC

ISSN Eletrônico 2358-9426 e ISSN Impresso 1413-8131

\section{REFERÊNCIAS}

AFUMAG. Resíduos: gerenciamento os resíduos sólidos urbanos em etapas. Minas Gerais, 2013. Disponível em: <https://www.ufmg.br/ead/sistemas/fip/page2.4.html>. Acesso em: 15 jul. 2016.

ASSOCIAÇÃO BRASILEIRA DE NORMAS TÉCNICAS: NBR-10004: 2004. resíduos sólidos. Rio de Janeiro: ABNT, 200471 p..

NBR-11174: Armazenamento de resíduos classes II - não inertes e III - inertes. Rio de Janeiro, 1990.7 p.

$1992.14 \mathrm{p}$

NBR-12235: Armazenamento de resíduos sólidos perigosos. Rio de Janeiro,

NBR-13221: Transporte terrestre de resíduos. Rio de Janeiro, 2003.4 p.

NBR-7500: Identificação para o transporte terrestre, manuseio, movimentação e armazenamento de produtos. Rio de Janeiro, 2011.59.p.

AMARO, Ana. PÓVOA, Andréia. MACEDO, Lúcia. A arte de Fazer Questionários. Porto Alegre, 2005.11p.

BARBIERI, José Carlos. Gestão Ambiental Empresarial: conceitos, modelos instrumentos. Saraiva. São Paulo, 2004.328 p.

BELlO, José Luiz de Paiva. Instrumentos de Coleta de Dados. Rio de Janeiro, 2004. Disponível em: < http://www.pedagogiaemfoco.pro.br/met06.htm>. Acesso em: 11 jul. 2016.

BRASIL, Anna Maria; SANTOS, Fátima. Equilíbrio Ambiental e Resíduos na Sociedade Moderna. São Paulo. Editora Faarte. 2007. 255 p.

BRASIL, Lei n. 12.305 de 2 de agosto de 2010: Institui a Política Nacional de Resíduos Sólidos; altera a lei n. 9.605, de 12 de fevereiro de 1998; e da outras providencias. Diário oficial da união. 03 ago. 2010 Disponível em: <http://www.planalto.gov.br/ccivil_03/_ato20072010/2010/lei/112305.htm>. Acesso em: 16 jul. 2016.

BRASIL, Lei n.13.557 de 17 de novembro de 2005: Dispõe sobre a Política Estadual de Resíduos Sólidos e Adota outras Providências. Diário Oficial da união. 17 nov. 2005. Disponível em:< http://www.ciflorestas.com.br/arquivos/lei_lei_13.5572005_17353.pdf $>$. Acesso em: 02 jul. 2016.

BRASIL, Portaria Minter n. 53, de março de 1979: Dispõe sobre o destino e tratamento de resíduos; Diário Oficial da republica federativa do Brasil. Brasília/DF, 08 mar. 1979. Disponível

em:

<http://www.mp.sc.gov.br/legisla/fed_ato_port_res/portaria/1950_1979/pf053_79.htm>.

Acesso em: 16 jul. 2016.

BRUGGER, Paula. Educação ou adestramento ambiental. 2. ed. Letras Contemporâneas. Florianópolis, 1994,142 p.

CARVALHOSA, Susana Fonseca, DOMINGOS, Ana, SEQUEIRA, Cátia. Modelo lógico de um programa de intervenção comunitária gerações. Análise Psicológica, v.28, n.3. Lisboa, 2010. Disponível em: $<\mathrm{http}: / / \mathrm{www}$.scielo.gpeari.mctes.pt/scielo.php?pid=S0870$82312010000300008 \&$ script=sci_arttext $\rangle$.Acesso em: 27 jul. 2016.

CORREIA, Sílvia Lizi Gonçalves de Castro. Educação Ambiental numa empresa Petroquímica. 2010. 75 f. Dissertação (Mestrado em Biologia) - Faculdade de Ciências da 
Revista Tecnologia e Ambiente, v. 23, 2017, Criciúma, Santa Catarina/SC

ISSN Eletrônico 2358-9426 e ISSN Impresso 1413-8131

Universidade do Porto - Porto, 2010. Disponível em: $<$ http://www.fc.up.pt/pessoas/ptsantos/teses/tese-SCorreia2010-

EdicacaoAmbiental_numa_empresa_petroquimica.pdf> Acesso em: 16 jul. 2016.

FARIA. Camila Conceição. Cooperativismo. São Paulo, 2013a. Disponível em: <http://www.infoescola.com/sociologia/cooperativismo/>. Acesso em: 15 jul. 2016.

FARIA, Caroline. Definição de Resíduos Sólidos. Rio de Janeiro, 2013b. Disponível em: <http://www.infoescola.com/ecologia/definicao-de-residuos-solidos/>. Acesso em: 16 jul. 2016.

FARIA, Caroline. Classificação e Tipos de Resíduos Sólidos. Rio de Janeiro, 2013c. Disponível em: <http://www.infoescola.com/ecologia/residuos-solidos/>. Acesso em: 23 jul 2016.

FARIA, Caroline. Destinação de Resíduos. Rio de Janeiro, 2013d. Disponível em: <http://www.infoescola.com/ecologia/destinacao-de-residuos/>. Acesso em: 09 jul. 2016.

FECOERUSC. Federação de Cooperativas de Energia do Estado de Santa Catarina. Rio Grande do Sul, 2004. Disponível em: $<$ http://www.fecoerusc.org.br/paginas_htm/federacao_organizacao.htm>. Acesso em: 15 jul. 2016.

FUZARO, João Antonio. CETESB - Companhia de Tecnologia de Saneamento Ambiental. Compêndio sobre tratamento disposição de resíduos sólidos. São Paulo, 2001,16 p.

JUNIOR, Arlindo Philippi. Saneamento, Saúde e Ambiente: fundamentos para um desenvolvimento sustentável. Baueri-SP: Manole, 2005. 842 p. (Coleção Ambiental 2).

JUNIOR, Gersina N. da R. Carmo. Resíduos Sólidos Acondicionamento. 2010, 20p. Disponível em: $<$ http://docplayer.com.br/17255124-Residuos-solidos-acondicionamentogersina-n-da-r-carmo-junior.html >. Acesso em: 05 jul. 2016.

KNOBEL, Márcia Gil. Qualidade Ambiental e Educação Ambiental em Empresas: estudo de caso. São Paulo, 1997,19 p. Disponível em: < http://engema.org.br/VIENGEMA/anais2001.pdf >. Acesso em: 09 jul. 2016.

LIMA, José Dantas de. Gestão de Resíduos Sólidos Urbanos no Brasil. Paraíba, 2005. Ed Abes. 267 p.

MACEDO, Silvia Regina Kruger. Análise do Funcionamento de Programas de Educação Ambiental Implantados em uma Siderúrgica em Cariacica (ES). 2009. 77 p. Dissertação (Mestrado em Ecologia de Ecossistemas). Centro Universitário, Vila Velha, 2009.

MUNDOCOOP. Cooperativas de Energia proporcional Inclusão. Brasília, 2013. Disponível em: <http://mundocoop.com.br/momentocooperar/?page_id=203>. Acesso em: 15 jul. 2016.

MORALES, Angélica Góis Muller. A Importância da Educação Ambiental no Processo de Gerenciamento Sócio Ambiental. Doutoranda em Meio Ambiente e Desenvolvimento, Made, UFPR/PR.2007,4p.Disponivel em; < http://www.comscientianimad.ufpr.br/artigos/analiseinterpretativa.rodrigues.pdf>.Acesso em: 28 jul. 2016.

OLIVEIRA, Franciclei de Palhano de. O meio ambiente e o setor industrial: desafio para o desenvolvimento sustentável. Pernambuco, 2002. 69p. Disponível em:<http://www.cprh.pe.gov.br/downloads/meio-ambiente.pdf>. Acesso em 16 jul. 2016.

PRADO, Alexandre. Educação Ambiental Formal e Não Formal. Mato Grosso do Sul, 2009. 24 


\section{Revista Tecnologia e Ambiente, v. 23, 2017, Criciúma, Santa Catarina/SC}

ISSN Eletrônico 2358-9426 e ISSN Impresso 1413-8131

<www.ficms.com.br/.../EDUCAcaO_AMBIENTAL_FORMAL_E_NaO_FORMAL.ppt Acesso em: 09 jul. 2016.

PEREGRINI, M.A.; RIBEIRO, F.S.; PAZZINI, H.A. As cooperativas de Eletrificação Rural no Novo Cenário do Setor Elétrico. Scielo. São Paulo, 2004. Disponível em: $<$ http://www.proceedings.scielo.br/scielo.php?pid=MSC0000000022004000100017\&script=s ci_arttext>. Acesso em: 16 jul. 2016.

PINTO, Tarcísio de Paula. Guia para Elaboração dos Planos de Gerenciamento de Resíduos Sólidos: Ministério do Meio Ambiente. Brasília - DF, 2011. Disponível em: $<$ http://www.cidadessustentaveis.org.br/sites/default/files/arquivos/guia_elaboracao_planos_g estao_residuos_solidos_mma.pdf>. Acesso em: 13 jul. 2016.

QUINTIERI, Marcelo. O Destino Final de Resíduos e Rejeitos. Rio de Janeiro, 2013. Disponível em: <http://blogdoquintiere.wordpress.com/2013/01/25/o-destino-final-deresiduos-e-rejeitos/>. Acesso em: 09 jul. 2016.

RESOL. Manual de Gerenciamento de Resíduos de Saúde. São Paulo.2012. Disponível em: <http://www.resol.com.br/cartilha11/index.php>. Acesso em: 05 jul. 2016.

Resolução NORMATIVA n. 333 de 02 de dezembro de 1999: Estabelece as condições gerais para a implantação de instalações de energia elétrica de uso privativo, dispõe sobre a permissão de serviços públicos de energia elétrica e fixa regras para regularização de cooperativas de eletrificação rural. Diário Oficial da União. Brasília, DF, 03 dez. 1999. Disponível em: <http://www.aneel.gov.br/cedoc/ren2008333.pdf>. Acesso em: 16 jul. 2016.

. Resolução CONAMA n. 307 de 05 de julho de 2002: Estabelece diretrizes, critérios e procedimentos para a gestão dos resíduos da construção civil. Diário Oficial da União. Brasília, DF, 012009.2 Disponível em: <http://www.mma.gov.br/port/conama/legiabre.cfm?codlegi=307>. Acesso em: 16 jul. 2016.

.Resolução CONAMA n. 313 de 29 de outubro de 2002: Dispõe sobre o Inventário Nacional de Resíduos Sólidos Industriais. Diário Oficial da União. Brasília, DF, 22 nov. 2002. Disponível em: <http://www.mma.gov.br/port/conama/legiabre.cfm?codlegi=335>. Acesso em: 16 jul. 2016.

.Resolução CONAMA n. 258 de 26 de agosto de 1999: Impõe obrigações às empresas fabricantes e às importadoras de pneumáticos e dá providência correlatas. Brasília: Diário Oficial da União. Brasília, DF, 02 dez. 999. Disponível em: <http://www.mma.gov.br/port/conama/legiabre.cfm?codlegi=258>. Acesso em: 16 de jul. 2016.

Resolução CONAMA n. 275 de 25 de abril de 2001: Estabelece o código de cores para os diferentes tipos de resíduos. Brasília: Diário Oficial da União. Brasília, DF, 19 ju. 2001. Disponível em: <http://www.mma.gov.br/port/conama/legiabre. cfm?codlegi=275>. Acesso em: 16 de jul. 2016.

Resolução CONAMA n. 416 de 30 de setembro de 2009: Dispõe sobre a prevenção à degradação ambiental. Diário Oficial da União. Brasília, DF, 01 out.2009. Disponível em: <http://www.mma.gov.br/port/conama/legiabre. cfm?codlegi=416>. Acesso em: 16 de jul. 2016.

Resolução CONAMA n. 401 de 04 de novembro de 2008: Estabelece os limites máximos de chumbo, cádmio e mercúrio para pilhas e baterias comercializadas no território nacional. Diário Oficial da União. Brasília, DF, 05 nov. 2008. Disponível em: <http://www.mma.gov.br/port/conama/legiabre. cfm?codlegi=401>. Acesso em: 16 jul. 2016. 


\section{Revista Tecnologia e Ambiente, v. 23, 2017, Criciúma, Santa Catarina/SC ISSN Eletrônico 2358-9426 e ISSN Impresso 1413-8131}

Resolução CONAMA n. 422 de 23 de março de 2010: Estabelece diretrizes para as campanhas, ações e projetos de Educação Ambiental, conforme Lei n. 9.795, de 27 de abril de 1999, e dá outras providências. Diário Oficial da União. Brasília, DF, 24 mar, 2010. Disponível em: <http://www.mma.gov.br/port/conama/legiabre.cfm?codlegi=622>. Acesso em: 16 de jul. 2016.

RIBEIRO, José Claúdio Junqueira. Inventário de Resíduos Sólidos Industriais. Feam. Belo Horizonte, sd. Disponível em: <http://www.bvsde.paho.org/bvsaidis/puertorico29/junqueira.pdf>. Acesso em: 06 jul 2016.

ROSSETI, G.C. et al. Regularização das Cooperativas Regionais de Eletrificação Rural do Alto Uruguai: Creral, como agente prestador do serviço público de Distribuição de Energia Elétrica e suas vantagens e desvantagens. Rio de Janeiro, v 4, n. 8. 2009, 18 p.. Disponível em: <http://www.ideau.com.br/getulio/upload/artigos/art_22.pdf>. Acesso em: 16 jul. 2016.

SANTA CATARINA. Decreto n. 14.250 de 05 de junho de 1981. Regulamenta dispositivos da Lei n. 5.793, de 15 de outubro de 1980, referente à proteção e melhoria da qualidade ambiental. Diário Oficial de Santa Catarina. 09 ju. 1981. Disponível em: <http://www2.rio.rj.gov.br/smu/buscafacil/Arquivos/PDF/D12250M.PDF>. Acesso em: 16 jul. 2016.

SANTA CATARINA. Decreto $\mathrm{n}^{\circ} 3.726$ de 14 de dezembro de 2010.Regulamenta o Programa de Educação Ambiental de Santa Catarina ProEEA/SC. Diário Oficial de Santa Catarina. 16 dez. 2010. Disponível em: <http://server03.pge.sc.gov.br/LegislacaoEstadual/2010/003726005-0-2010-003.htm.>. Acesso em: 16 jul. 2016.

SANTA CATARINA. Decreto $\mathrm{n}^{\circ} 4.281$ de 25 de junho de 2002. Regulamenta a Lei $\mathrm{n}^{\mathrm{o}}$ 9.795, de 27 de abril de 1999, que institui a Política Nacional de Educação Ambiental, e dá outras providências. Diário Oficial de Santa Catarina. 26 jun. 2002. Disponível em:< http://www.planalto.gov.br/ccivil_03/decreto/2002/D4281.htm>. Acesso em: 23 jul. 2016.

SANTA CATARINA. Decreto $n^{\circ} 41.019$ de 26 de fevereiro de 1957. Regulamenta os serviços de energia elétrica. Diário Oficial de Santa Catarina. 27 fevereiro 1957. Disponível em:< http://www.planalto.gov.br/ccivil_03/decreto/Antigos/D41019.htm>. Acesso em: 16 jul. 2016.

SANTA CATARINA. Decreto nº 62.655 de 03 de maio de 1968. Regulamento a execução de Serviços de Eletrificação Rural mediante autorização para uso privativo, e dá outras providências. Ver tópico (14 documentos). Diário Oficial de Santa Catarina. 07 maio 1958. Disponível em:< http://www2.camara.leg.br/legin/fed/decret/1960-1969/decreto-62655-3maio-1968-404056-norma-pe.html>. Acesso em: 16 jul. 2016.

SANTA CATARINA. Decreto $\mathrm{n}^{\circ} 1.033$ de 22 de maio de 1962. Altera o art. 177, do Decreto $\mathrm{n}^{\circ}$ 41.019, de 26 de fevereiro de 1957, que passa, a ter a seguinte alínea: XI - cooperativas rurais. Diário Oficial de Santa Catarina. 24 maio 1962. Disponível em:< http://www.planalto.gov.br/ccivil_03/decreto/Historicos/DCM/dcm1033.htm>. Acesso em : 26 jul. 2016.

SANTA CATARINA. Decreto $\mathrm{n}^{\circ} 4.281$ de 25 de junho de 2002. Regulamenta a Lei no 9.795 , de 27 de abril de 1999, que institui a Política Nacional de Educação Ambiental, e dá outras providências. Diário Oficial de Santa Catarina. 26 jun. 2002. Disponível em:< http://www.planalto.gov.br/ccivil_03/decreto/2002/D4281.htm>. Acessado em: 23 jul. 2016.

SANTA CATARINA. Lei $\mathrm{n}^{0} 11.347$, de 17 de janeiro de 2000. Dispõe sobre a coleta, o recolhimento e o destino final de resíduos sólidos potencialmente perigosos que menciona, e adota outras providências. Diário Oficial de Santa Catarina. 18 jan. 2000. Disponível em:< 
http://www.carvaomineral.com.br/abcm/meioambiente/legislacoes/bd_carboniferas/residuo/le i_estadual_11347-2000.pdf > Acesso em: 16 jul. 2016.

SANTA CATARINA. Lei ${ }^{0} 12.863$, de 12 de janeiro de 2004. Dispõe sobre a obrigatoriedade do recolhimento de pilhas, baterias de telefones celulares, pequenas baterias alcalinas e congêneres, quando não mais aptas ao uso e adota outras providências. Diário Oficial de Santa

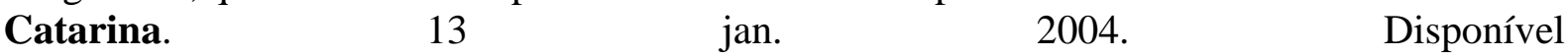
em: <http://www.carvaomineral.com.br/abcm/meioambiente/legislacoes/bd_carboniferas/resid uo/lei_estadual_12863-2004.pdf >. Acesso em: 16 jul. 2016.

SANTA CATARINA. Lei ${ }^{0} 14.675$, de 13 de abril de 2009. Institui o Código Estadual do Meio Ambiente e estabelece outras providências. Diário Oficial de Santa Catarina. 14 abr. 2009. Disponível em: < http://www.cooperalfa.com.br/2010/arquivos/codigo_ambiental.pdf >. Acesso em: 16 jul. 2016.

Lei no 9.797 de 27 de abril de 1999. Dispõe sobre a educação ambiental, institui a Política Nacional de Educação Ambiental e dá outras providências. Diário Oficial da União. 27 abr. 1999. Disponível em: <http://www.planalto.gov.br/ccivil_03/Leis/L9795.htm> Acesso em: 16 jul. 2016.

SEMAD. Gerenciamento dos Resíduos Sólidos. Fortaleza, 2010. Disponível em: <http://www.semace.ce.gov.br/gerenciamento-dos-residuos-solidos/>. Acesso em: 05 jul. 2016.

SESCOOP. Serviço Nacional de Aprendizagem do Cooperativismo. Brasília, 2008. Disponível $\mathrm{em}:<$ http://www.brasilcooperativo.coop.br/site/transparenciasescoop/gestaoun/UN-2008.pdf>. Acesso em: 22 jul. 2016.

SILVA, David. Inventário de Resíduos: desenvolvimento do banco de dados de inventário de resíduo BD_IR. Manaus. sd. Disponível em: <http://www.suframa.gov.br/publicacoes/jica/ses_5_wi_pt_final_2.pdff>Acesso em: 06 jul. 2016.

VALLE, Cyro E. do. Como se preparar para as normas ISO 14000: qualidade ambiental. São Paulo: Pioneira, 2002.

VILELA JÚNIOR, Alcir; DEMAJORVIC, Jacques. Modelos e ferramentas de gestão ambiental: desafios e perspectivas para as organizações. São Paulo: SENAC/SP, 2006. 396 p.

VILHENA, A. Lixo Municipal: manual de gerenciamento integrado. São Paulo: CEMPRE, 2010. 350 p. 